\title{
Atrofia e regeneração da glândula parótida após ligadura do ducto excretor: estudo histológico e histoquímico em ratos.
}

\author{
TATIANA VARAS SIQUEIRA* ; CARLOS EDUARDO DIAS COLOMBO**; IVAN BALDUCCI***; \\ YASMIN RODARTE CARVALHO****
}

\section{Resumo}

O objetivo deste trabalho foi estudar a atrofia unilateral da glândula parótida de ratos, após a ligadura do ducto excretor, e a regeneração glandular, através de ligadura ductal seguida pela remoção da obstrução após sete dias, analisando as alterações morfológicas glandulares e o potencial proliferativo dos ductos intercalares. Análise morfológica foi também realizada na parótida contralateral. Os ratos foram sacrificados e suas glândulas foram processadas e submetidas às colorações histológicas (HE e PAS) e histoquímica (AgNOR). Durante a atrofia glandular, houve degeneração e redução do parênquima, assim como inflamação e fibrose. Durante a regeneração glandular, houve o restabelecimento do parênquima e redução da inflamação e da fibrose. Nas glândulas contralaterais, houve desorganização e degeneração teciduais. Não foi observada alteração do potencial proliferativo dos ductos intercalares durante o experimento.

\section{UNITERMOS}

Glândula parótida, atrofia, regeneração; AgNOR.

SIQUEIRA, T.V. et al. Atrophy and regeneration of parotid gland after excretory duct ligature: histologic and histochemical study in rats. PGR Pós-Grad Rev Fac Odontol São José dos Campos, v.5, n.1, jan./abr. 2002.

\footnotetext{
Abstract

The purpose of this work was to study the unilateral atrophy of rat parotid gland, after excretory duct ligature, and gland regeneration, through duct ligature followed by removal of the obstruction after seven days, analysing gland morphologic alterations and the proliferative potencial of intercalated ducts. Morphologic analysis was also performed on the contralateral parotid. Rats were sacrificed and their glands were processed and submitted to histologic (HE e PAS) and histochemical (AgNOR) stainings. Degeneration and reduction of
}

parenchyma were observed, as well as inflammation and fibrosis during gland atrophy. There was recovery of parenchyma and reduction of inflammation and fibrosis during gland regeneration. There was disorganization and degeneration of tissue of contralateral glands. No alteration of the proliferative potencial of intercalated ducts was observed throughout the experiment.

\section{UNITERMS}

Parotid gland, atrophy, regeneration; AgNOR.

\section{INTRODUÇÃO}

Os processos de atrofia das glândulas salivares devido a sialadenites crônicas, sialolitíases, Síndrome de Sjögren e radioterapia são importantes problemas clínicos ${ }^{3}$.

Muitos são os trabalhos que estudam a atrofia e regeneração de glândulas salivares ${ }^{2-4,10,12-3,15}$, sendo que o crescente interesse pelo assunto tem como objetivo criar condições que possibilitem o estabelecimento de estratégias para tratar ou reverter os efeitos da atrofia glandular ${ }^{3}$.

Diversos estudos demonstraram alterações a partir da ligadura e obstrução do ducto principal da glândula parótida, destacando-se a redução gradual e acentuada das células acinares e a persistência de estruturas ductais $2,3,4,12,15$. No processo de regeneração glandular, após a remoção da ligadura e desobstrução do ducto, observa-se aumento gradativo do número e tamanho dos ácinos, que se desenvolvem entre os ductos persistentes ${ }^{2,3,12,15}$.

\footnotetext{
* Bolsista de Iniciação Científica do Programa PIBIC/CNPq - Faculdade de Odontologia de São José dos Campos - UNESP - Cep 12245-000.

** Aluno do Programa de Pós-Graduação - Área de Concentração em Biopatologia Bucal (Nível Doutorado) - Faculdade de Odontologia de São José dos Campos - UNESP - Cep 12245-000.

*** Departamento de Odontologia Social e Clínica Infantil - Faculdade de Odontologia de São José dos Campos - UNESP - Cep 12245-000 ****Departamento de Biociências e Diagnóstico Bucal - Faculdade de Odontologia de São José dos Campos - UNESP - Cep 12245-000.
} 
O modelo experimental de atrofia e regeneração da parótida tem sido também utilizado para a determinação da capacidade proliferativa de células glandulares 2, 4, 15. Diferentes métodos podem ser utilizados para detectar e quantificar células em proliferação. Dentre eles temos: contagem do número de mitoses, citometria de fluxo, incorporação de precursores do DNA (timidina tritiada, BrdU), detecção de antígenos associados à proliferação celular (Ki-67, PCNA) e a técnica do Ag$\mathrm{NOR}^{6}$. Tal técnica consiste na visualização das regiões organizadoras nucleolares (NORs), através do emprego do nitrato de prata para coloração das proteínas associadas a essas regiões ${ }^{11}$. As NORs são alças de DNA que possuem os genes para a transcrição de RNA ribossômico, o qual é importante para a formação de ribossomos e, conseqüentemente, para a síntese proteica ${ }^{1}$. Nas células em proliferação, aumenta-se o número de NORs, tornando-se possível a relação entre a contagem de NORs e a proliferação celular ${ }^{5}$.

A apreciação da complexidade das glândulas salivares quanto à sua capacidade regenerativa constitui importante subsídio para compreensão dos processos patológicos originados nas mesmas. Diante do exposto, a proposta deste trabalho foi estudar a atrofia unilateral da parótida de ratos, após a ligadura do ducto excretor, e a regeneração glandular, após a desobstrução do mesmo, analisando as alterações morfológicas glandulares, bem como o potencial proliferativo dos ductos intercalares obtido através da técnica do AgNOR. Análise morfológica foi também realizada na parótida contralateral.

\section{Materiais e mÉtodos}

Foram utilizados cinquenta ratos machos adultos, da raça Wistar, com noventa dias de idade e peso em torno de $250 \mathrm{~g}$, sendo o trabalho dividido em duas partes. Na primeira, foram examinadas as alterações celulares ocorridas na atrofia glandular e, na segunda, a capacidade de regeneração celular após essa atrofia, estudando também as respectivas glândulas contralaterais durante todo o experimento.

Para a realização dos procedimentos cirúrgicos, os ratos foram pesados e anestesiados com solução de cloridrato de 2-(2,6-xilidino)-5,6dihidro-4H- 1,3-tiazina (Rompum - Bayer S.A. - Saúde Animal) + ketamina base (Francotar - Virbac do Brasil Ind. e Com. LTDA) na proporção de 1:0,5, administrando-se $0,1 \mathrm{ml} / 100 \mathrm{~g}$ por via intramuscular.

Em um grupo de vinte ratos, foi realizada a tricotomia e uma incisão de aproximadamente $3,0 \mathrm{~cm}$ na pele da região do pescoço do lado direito. Depois da divulsão dos tecidos, o ducto excretor da glândula parótida direita foi identificado e isolado na superfície do músculo masseter. Nesse ducto foi realizada uma ligadura para se obter a obstrução de sua luz, buscando-se assim a atrofia glandular. O mecanismo de obstrução ductal consistiu inicialmente na utilização de um fio de algodão $n^{\circ}$ 8.0, o qual foi passado por trás do referido ducto. Posteriormente, as duas extremidades desse fio foram passadas pelo interior de um tubo de polietileno de $4,0 \mathrm{~mm}$ de comprimento e $1,1 \mathrm{~mm}$ de diâmetro, através do uso de uma agulha. A seguir, esse tubo foi levado até junto ao ducto excretor e então realizado um nó com as duas extremidades do fio de algodão, com pressão suficiente para causar obstrução desse ducto, porém, sem lesar o mesmo. Os tecidos foram reposicionados e a incisão suturada. Os animais foram sacrificados com dose excessiva do anestésico em grupos de cinco, nos períodos de 1, 5, 7 e dez dias após a amarria. Ambas as glândulas parótidas foram removidas de cada animal.

Para o estudo da regeneração glandular, foram utilizados outros 25 ratos, nos quais o ducto excretor da glândula parótida direita foi exposto e obstruído como descrito anteriormente. Porém, após sete dias, foi realizada uma nova incisão e a ligadura ductal foi removida cirurgicamente, através do corte do tubo de polietileno com tesoura, livrando-se automaticamente do nó realizado e desobstruindo-se o ducto. A partir de então, os animais foram sacrificados em grupos de cinco, nos períodos de 1, 3, 5, 7 e 14 dias. Ambas as glândulas parótidas foram excisadas.

Cinco ratos não operados previamente foram sacrificados e suas parótidas compuseram o grupo do dia zero (controle) das glândulas em atrofia e das glândulas opostas às glândulas em atrofia. Para compor o grupo do dia zero (controle) das glândulas em regeneração, foram utilizadas as glândulas com sete dias de atrofia. As glândulas opostas às glândulas com 7 dias de atrofia foram utilizadas 
para compor o grupo do dia zero (controle) das glândulas opostas às glândulas em regeneração.

Os espécimes foram fixados em formol a $10 \%$ e incluídos em parafina. Foram feitos cortes de $3 \mathrm{~mm}$ de espessura, os quais foram submetidos às colorações pela hematoxilina e eosina (HE) e pelo método do ácido periódico de Schiff (PAS) e à reação histoquímica do AgNOR.

Na técnica histoquímica do AgNOR, após desparafinização e desidratação, os cortes histológicos seguiram os seguintes passos: imersão em solução de ácido acético/etanol (1:3); lavagem em etanol absoluto; imersão dos cortes em celuidina a $1 \%$, em etanol/éter ( $1: 1)$; secagem da lâmina; imersão em etanol a 70\%; lavagem em água destilada e incubação com solução aquosa de nitrato de prata a $50 \%$, misturada à solução de gelatina em ácido fórmico aquoso a $1 \%$, na proporção de $2: 1$, na estufa a $45^{\circ} \mathrm{C}$, por $20 \mathrm{~min}$. A seguir, os cortes foram lavados em água destilada a $45^{\circ} \mathrm{C}$, desidratados, clareados e montados em Permount.

As colorações de HE e PAS foram analisadas qualitativamente através de microscópio de luz.

Foram obtidos os índices de AgNOR apresentados pelas células dos ductos intercalares nas glândulas em atrofia e regeneração. Os pontos de NORs distintos em cada núcleo foram contados em cem células em cada glândula, através de microscópio de luz (1000X). Foi realizada a média e calculado o desvio-padrão (DP) dos números de NORs/núcleo obtidos nos diferentes prazos estudados. Posteriormente, os índices de AgNOR foram submeti-

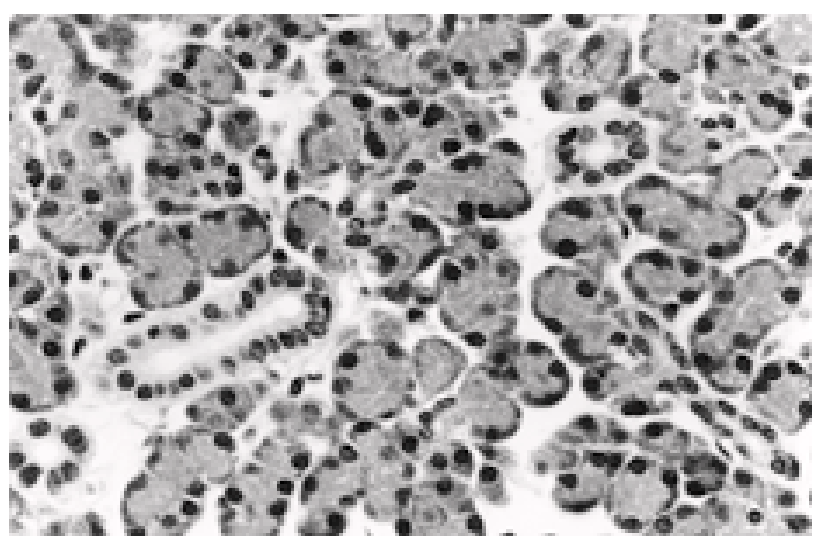

FIGURA 1 - Ácinos, ductos intercalares e ducto estriado no dia zero (controle da glândula em atrofia). HE, aumento original $630 X$ dos à Análise de Variância a um critério (ANOVA) em cada situação proposta. O nível de significância foi fixado em 0,05 .

\section{Resultados}

\section{AnÁlise morfológica}

\section{Atrofia glandular}

As parótidas do dia zero (controles) exibiram parênquima constituído por ácinos serosos e ductos intercalares, estriados e excretores, além de estroma constituído por tecido conjuntivo fibroso (Figura 1). Com um dia de atrofia, observaram-se ductos dilatados com acúmulo de secreção em sua luz, contendo células inflamatórias, principalmente neutrófilos. Após esse período, o estroma apresentou vasodilatação, congestão vascular, edema e infiltrado inflamatório basicamente mononuclear. Com cinco dias de atrofia, verificou-se a redução dos ácinos em volume e quantidade, estando localizados, principalmente, na periferia dos lóbulos. Havia também discreta vacuolização tecidual e, no estroma, moderada fibrose. Aos 7 dias, ácinos remanescentes estavam presentes em menor quantidade, os quais, juntamente com os ductos, apresentavam vacuolizações mais acentuadas (Figura 2). Já aos dez dias, foram encontrados escassos ácinos remanescentes, observando-se também aumento da fibrose. Durante a atrofia glandular, verificou-se redução acentuada dos grânulos de secreção PAS-positivos em ácinos e ductos (Figura 3).

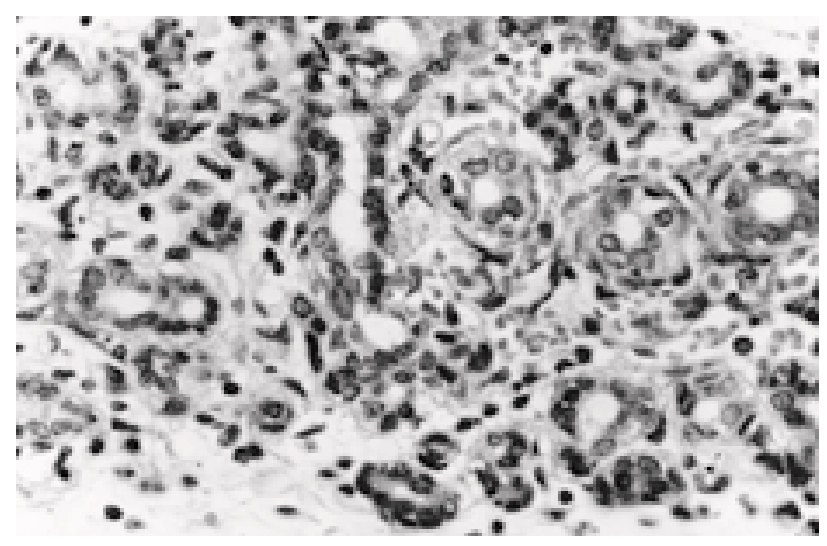

FIGURA 2 - Processo inflamatório e presença de vacuolizações em ácinos e ductos na glândula com 7 dias de atrofia. HE, aumento original $630 \mathrm{X}$. 


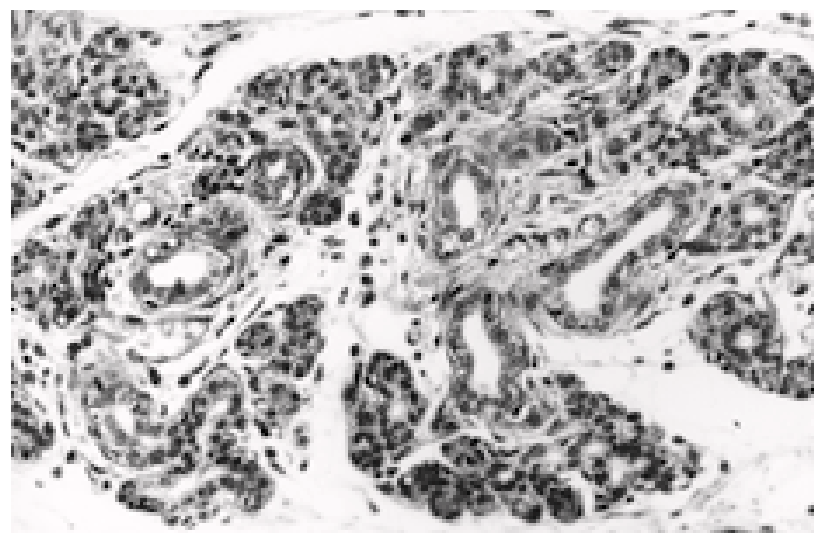

\section{Regeneração gLANDULAR}

Após um dia, observou-se discreto aumento da quantidade dos ácinos, os quais estavam localizados, principalmente, na periferia dos lóbulos. A partir desse período, verificou-se uma diminuição na incidência de vacuolizações nas células acinares e ductais. Com 3 dias, os ductos estavam menos dilatados. A partir de então, notou-se aumento da quantidade e volume dos ácinos, os quais, gradativamente, passaram a ocupar toda a extensão lobular (Figura 4). Finalmente aos 14 dias, observaram-se ácinos volumosos dispostos em arranjo denso e apresentando, juntamente com os ductos, aspecto de normalidade. Durante a regeneração, houve redução da inflamação e da fibrose, sendo que, ao final da mesma, o estroma de tecido conjuntivo formava septos delicados entre os lóbulos. Observou-se também aumento gradual da quantidade

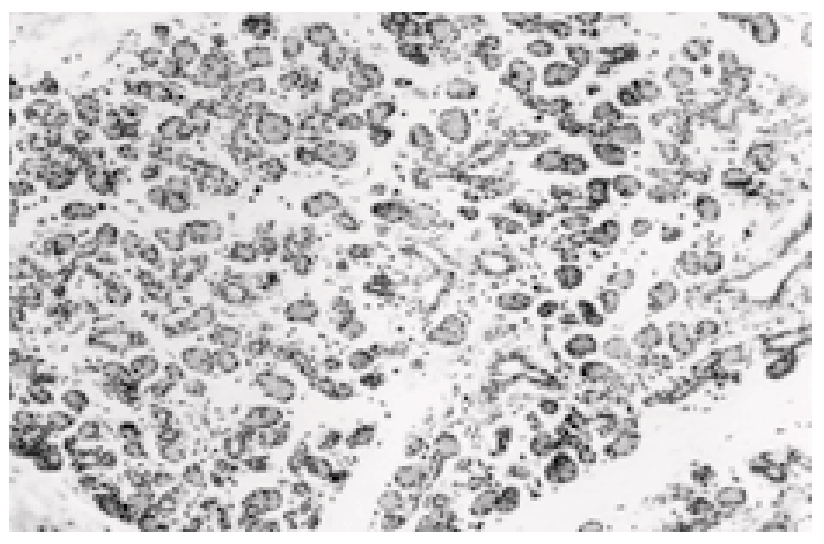

FIGURA 4 - Ácinos numerosos na glândula com 7 dias de regeneração. HE, aumento original $200 X$.
FIGURA 3 - Ácinos residuais na periferia do lóbulo, contendo grânulos de secreção PAS-positivos com 10 dias de atrofia glandular. PAS, aumento original $400 \mathrm{X}$.

de grânulos PAS-positivos em ácinos e ductos intercalares (Figura 5).

\section{GLÂNDULAS OPOSTAS Às GLÂNDULAS EM ATROFIA}

Nas glândulas do dia zero, foram observados ductos e ácinos com aspecto de normalidade, apresentando, por vezes, poucos vacúolos claros intracelulares. A partir do primeiro dia, verificou-se uma desorganização arquitetural glandular, notando-se ácinos mal definidos. Com sete dias, houve um moderado aumento de vacuolizações no interior das células acinares, que, aos dez dias, exibiram grande número de vacúolos claros de tamanho variado. Notou-se também maior desorganização tecidual no décimo dia, além de grande quantidade de grânulos PAS-positivos nos ácinos e ductos intercalares (Figura 6).

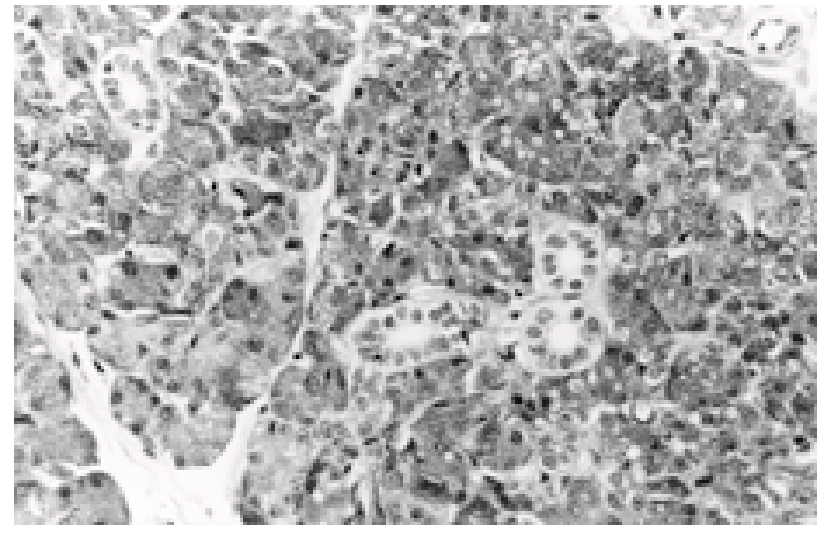

FIGURA 5- Parênquima com aspecto de normalidade e ausência de sinais inflamatórios na glândula com 14 dias de regeneração. PAS, aumento original 400X. 


\section{GLÂNDULAS Opostas Às GLÂndulas EM REGENERAÇÃO}

Nas glândulas do dia zero, assim como nas glândulas dos outros períodos, notaram-se áreas de desorganização tecidual, com ácinos mal definidos, os quais apresentavam moderada quantidade de vacuolizações. Grânulos PAS-positivos foram observados em grande quantidade nos ácinos e ductos intercalares.

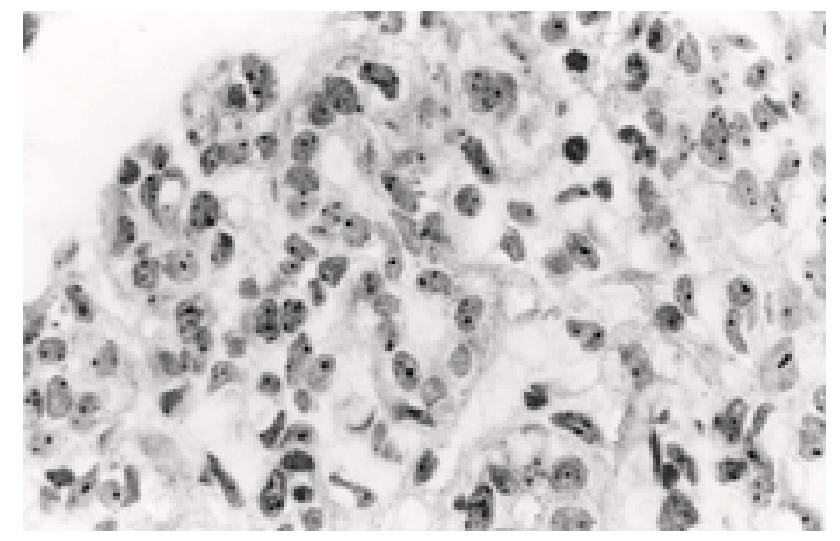

FIGURA 7 - Glândula com 7 dias de atrofia. AgNOR, aumento original $1000 \mathrm{X}$.
ÍNDICES PROLIFERATIVOS - AGNOR

As NORs foram observadas como pontos acastanhados a negros no interior dos núcleos celulares, variando em número, forma e tamanho (Figura 7).

ANOVA mostrou que não houve diferença estatisticamente significante entre os índices médios de AgNOR apresentados pelas células dos ductos intercalares nas glândulas em atrofia e nas glândulas em regeneração, sendo estatisticamente iguais aos respectivos controles ( $\mathrm{p}>0,05$; Tabela 1$)$

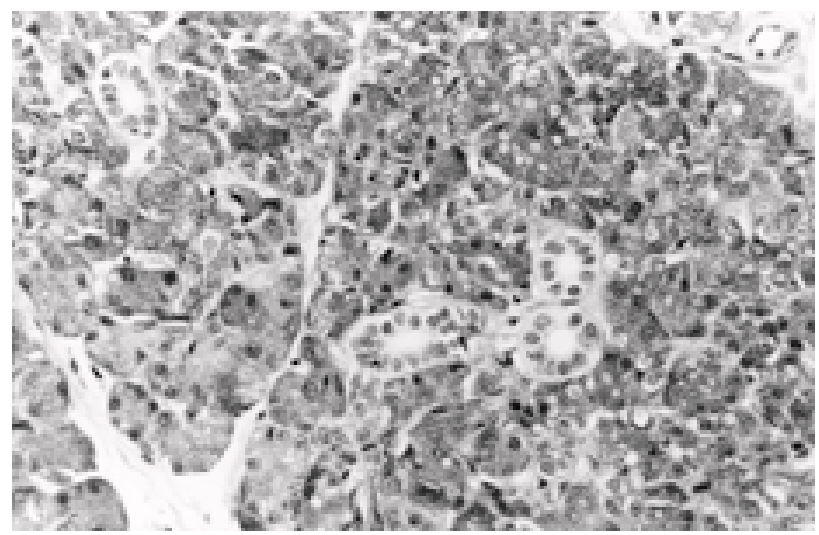

FIGURA 6 - Área de desorganização estrutural e vacuolizações na glândula oposta à glândula com 10 dias de atrofia. PAS, aumento original $400 \mathrm{X}$.

Tabela 1 - Médias ( \pm DP) dos índices de AgNOR apresentados pelas células dos ductos intercalares nas glândulas em atrofia $(A)$ e nas glândulas em regeneração (B).

\begin{tabular}{ccc}
\hline & $\begin{array}{c}\text { Tempo } \\
\text { (dias) }\end{array}$ & $\begin{array}{c}\text { AgNOR } \\
\text { (no NORs / núcleo) }\end{array}$ \\
\hline & 0 & $1,62 \pm 0,07$ \\
$1,67 \pm 0,18$ \\
& 1 & $1,50 \pm 0,05$ \\
& 5 & $1,51 \pm 0,07$ \\
& 7 & $1,58 \pm 0,03$ \\
\hline & 10 & $1,51 \pm 0,07$ \\
& 0 & $1,65 \pm 0,14$ \\
& 1 & $1,58 \pm 0,04$ \\
& 3 & $1,59 \pm 0,06$ \\
& 5 & $1,64 \pm 0,04$ \\
& 7 & $1,66 \pm 0,11$ \\
\hline
\end{tabular}




\section{Dıscussão}

Em nosso estudo, de modo geral, verificamos degeneração, atrofia e gradual redução das estruturas acinares, bem como dilatação, degeneração e persistência de ductos durante a atrofia da parótida.

A presença de estruturas ductais ou ductiformes durante a atrofia glandular tem sido relatada pela maior parte dos estudos ${ }^{2-4,9,10,12-7}$, sendo a dilatação ductal uma característica bastante mencionada $9,10,12,13,14,16,17$.

Quanto à capacidade proliferativa das células ductais durante a atrofia glandular, Walker \& Gobé ${ }^{16}$ (1987) verificaram um aumento dos índices de incorporação de ${ }^{3} \mathrm{H}$-timidina pelos ductos intercalares e estriados, além de um maior número de mitoses apresentado por esses ductos. BurfordMason et al. ${ }^{2}$ (1993), por sua vez, observaram que todos os tipos de ductos, sejam intercalares, estriados ou excretores, apresentaram maiores índices de PCNA quando comparados com os valores de controle. Segundo Takahashi et al. ${ }^{15}$ (1998), os índices de BrdU apresentados pelas células ductais também aumentaram durante a atrofia glandular. No entanto, os presentes resultados mostraram que não houve diferença estatisticamente significante entre os índices médios de AgNOR apresentados pelos ductos intercalares durante os diferentes períodos de atrofia da parótida, sendo inclusive estatisticamente iguais ao controle. Não verificamos, portanto, alteração do potencial proliferativo desses ductos durante a atrofia glandular.

Os trabalhos de atrofia glandular também relatam atrofia ${ }^{7-10,12-4,17}$ e degeneração dos ácinos ${ }^{14}$, além de perda das células acinares ${ }^{2-4,7,12,15-16}$, a qual ocorre através de apoptose $7,12,16$

Há controvérsias na literatura quanto ao desaparecimento ou persistência das células acinares durante a atrofia glandular. Trabalhos como os de Walker \& Gobé ${ }^{16}$ (1987) e Takahashi et al. ${ }^{15}$ (1998) referem-se ao desaparecimento dessas células após cinco e 7 dias de ligadura ductal, respectivamente. Esses trabalhos discordam de outros estudos, como os de Burford-Mason et al. ${ }^{2}$ (1993) e Burgess \& $\operatorname{Dardick}^{3}$ (1998), que relatam a persistência de células acinares por períodos maiores. Nossos resultados também mostraram a persistência das células acinares até 10 dias de ligadura ductal (maior período de atrofia estudado), sendo que essas células remanescentes foram localizadas, principalmente, na periferia dos lóbulos atróficos.

Segundo Takahashi et al. ${ }^{15}$ (1998), a persistência de células acinares após a obstrução ductal pode ser conseqüência de uma ligadura ductal incompleta. No entanto, em nosso trabalho, encontramos células acinares remanescentes mesmo tendo realizado uma ligadura completa do ducto excretor da parótida, com pressão suficiente para obstruir a luz desse ducto.

Quanto à presença de grânulos de secreção durante a atrofia glandular, verificamos através da coloração de PAS que, de um modo geral, houve uma redução desses grânulos nos ácinos remanescentes, assim como nos ductos. Walker \& Gobé ${ }^{16}$ (1987) observaram através de microscopia eletrônica a fusão intracitoplasmática de alguns grânulos de secreção nas células acinares e a liberação de outros no interior dos lumens acinares. Scott et al. ${ }^{12}$ (1999), por sua vez, verificaram também a redução desses grânulos em células acinares durante a atrofia da parótida.

No presente trabalho, observamos que, durante a regeneração glandular, houve aumento gradativo da quantidade e volume dos ácinos, redução da dilatação ductal e diminuição na incidência de vacuolização nas células acinares e ductais, sendo que a parótida apresentou aspectos de normalidade após 14 dias de regeneração.

O aumento da população de células acinares durante a regeneração glandular foi demonstrada nos trabalhos de Burford-Mason et al. ${ }^{2}$ (1993), Burgess $\& \operatorname{Dardick}^{3}$ (1998) e Takahashi et al. ${ }^{15}$ (1998).

Quanto à presença de ductos durante a regeneração da parótida, Burford-Mason et al. ${ }^{2}$ (1993) e Burgess \& $\operatorname{Dardick}^{3}$ (1998) verificaram, respectivamente, que as proporções apresentadas pelas células dos ductos intercalares e estriados e as áreas ocupadas por essas células retornaram aos valores de controle, já que haviam aumentado durante a atrofia glandular. Scott et al. ${ }^{12}$ (1999), por sua vez, observaram ductos dilatados até 14 dias de regeneração. Nesse prazo, porém, notamos em nossos espécimes ductos com aspecto de normalidade. Essa diferença pode ser reflexo do maior prazo de desobstrução ductal (14 dias de atrofia) utilizado por esses autores. Em nosso trabalho, diferentemente, utilizamos o prazo de sete dias de atrofia para realizar a desobstrução. 
Burford-Mason et al. ${ }^{2}$ (1993) observaram um modesto aumento dos índices de PCNA apresentados pelos ductos intercalares e estriados nas glândulas em processo regenerativo após desobstrução ductal. Takahashi et al. ${ }^{15}$ (1998), por sua vez, verificaram uma gradual redução dos índices de BrdU apresentados pelas células ductais nesse processo, já que esses índices eram elevados nas glândulas em atrofia. Em nosso estudo, no entanto, não observamos alteração do potencial proliferativo dos ductos intercalares nas glândulas em regeneração.

Através da coloração de PAS, observamos que, durante a regeneração glandular, houve um aumento dos grânulos de secreção nas células acinares, sendo que, inicialmente, esses grânulos apresentaram distribuição mais variada, a qual se tornou mais homogênea com a evolução do processo regenerativo. Através da microscopia eletrônica, Takahashi et al. ${ }^{15}$ (1998) verificaram também aumento dos grânulos de secreção em células acinares durante o desenvolvimento dessas células após desobstrução ductal, concordando com os nossos resultados.

Acreditando na atividade compensatória das glândulas contralaterais, resolvemos estudá-las no presente trabalho. Observamos desorganização da arquitetura glandular, havendo perda de definição do contorno e limite dos ácinos em algumas áreas, além de variada quantidade de vacuolizações, sendo que essas alterações foram encontradas tanto nas glândulas opostas às glândulas em atrofia, quanto nas glândulas opostas às glândulas em regeneração. Essas áreas de desorganização estrutural exibiram, por vezes, aspecto friável, refletindo, talvez, uma possível hiperplasia local, tornando o tecido mais celularizado. Quanto à presença de va-

\section{RefERÊNCIAS BIBLIOGRÁFICAS}

1. ALBERTS, B. et al. Molecular biology of the cell. 3.ed. New York: Garland, 1994. 1294p.

2. BURFORD-MASON, A.P. et al. Immunohistochemical analysis of the proliferative capacity of duct acinar cells during ligationinduced atrophy and subsequent regeneration of rat parotid gland. J Oral Pathol, v.22, n.10, p.440-6, Nov. 1993.

3. BURGESS, K. L.; DARDICK, I. Cell population changes during atrophy and regeneration of rat parotid gland. Oral Surg Oral Med Oral Pathol Oral Radiol Endod, v.85, n.6, p.699706, June 1998.

4. BURGESS, K. L. et al. Myoepithelial cells actively proliferate during atrophy of rat parotid gland. Oral Surg Oral cuolizações, essas podem estar ocorrendo devido a uma fadiga tecidual, visto que, provavelmente, as glândulas contralaterais sejam mais exigidas.

Dentre outros modelos experimentais, a literatura nos mostra que trabalhos de atrofia glandular após ligadura ductal, com ou sem estudo da regeneração após a desobstrução ductal, têm demonstrado a capacidade proliferativa de todas as células glandulares, tais como: as células acinares ${ }^{2,15,16}$, as células mioepiteliais ${ }^{4} \mathrm{e}$ as células ductais ${ }^{15}$, sejam dos ductos intercalares, estriados ${ }^{2,16}$ ou excretores ${ }^{2}$, reforçando a hipótese de que todas as células glandulares são potencialmente capazes de sofrer transformação neoplásica. Em nossos estudos, porém, encontramos baixos índices proliferativos dos ductos intercalares durante todo o experimento.

\section{Conclusões}

Com base nos resultados obtidos foi possível concluir que:

a) durante a atrofia glandular, ocorrem degeneração e redução do parênquima, desenvolvimento de processo inflamatório e fibrose;

b) durante a regeneração glandular, ocorrem restabelecimento do parênquima e redução do processo inflamatório e da fibrose;

c) nas glândulas contralaterais, ocorrem desorganização e degeneração da estrutura glandular;

d) avaliando-se os índices de AgNOR, não há alteração do potencial proliferativo dos ductos intercalares nas glândulas em atrofia e regeneração.

Med Oral Pathol Oral Radiol Endod, v.82, n.6, p.674-80, Dec. 1996.

5. DERENZINI, M.; TRERÈ, D. AgNOR proteins as a parameter of the rapidity of cell proliferation. Zentralbl Pathol, v.140, n.1, p.710, Mar. 1994.

6. HALL, P.A.; LEVISON, D.A. Review: assessment of cell proliferation in histological material. J Clin Pathol, v.43, n.3, p.18492, Feb. 1990.

7. HARRISON, J.D.; FOUAD, H.M.A.; GARRETT, J.R. The effects of ductal obstruction on the acinar cells of the parotid of cat. Arch Oral Biol, v.45, n.11, p.945-9, Nov. 2000.

8. HARRISON, J.D.; FOUAD, H.M.A.; GARRETT, J.R. Variation in response to ductal obstruction of feline submandibular and sublingual glands and the importance of the innervation. J Oral Pathol Med, v.30, n.1, p.29-34, Jan. 2001. 
9. HASHIMOTO, J. et al. Immunoreaction of keratin, actin, S-100 protein and rat-EGF in duct-ligated rat salivary glands. J Oral Pathol Med, v.21, n.5, p.214-20, May 1992.

10. OKAZAKI, Y. et al. Acceleration of rat salivary gland tissue repair by basic fibroblast growth factor. Arch Oral Biol, v.45, n.10, p.911-9, Oct. 2000.

11. PLOTON, D. et al. Improvement in the staining and the visualization of the argyrophilic proteins of nucleolar organizer region at the optical level. Histochem J, v.18, n.1, p.5-14, Jan. 1986.

12.SCOTT, J.; LIU, P.; SMITH, P.M. Morphological and functional characteristics of acinar atrophy and recovery in the duct-ligated parotid gland of the rat. J Dent Res, v.78, n.11, p.1711-9, Nov. 1999.

13.SHIMIZU, M.; YOSHIURA, K.; KANDA, S. Radiological and histological analysis of the structural changes in the rat parotid gland following release of Stensen's duct obstruction. Dentomaxillofac Radiol, v.23, n.4, p.197-205, Nov. 1994.

14.SOUZA, L.B. et al. Estudo esterológico da atrofia da glândula parótida do rato após ligadura do ducto excretor principal. Rev Odontol Univ São Paulo, v.9, n.1, p.1-9, jan./mar., 1995.

15.TAKAHASHI, S.; SCHOCH, E.; WALKER, N.I. Origin of acinar cell regeneration after atrophy of the rat parotid induced by duct obstruction. Int J Exp Pathol, v.79, n.5, p.293-301, Oct. 1998.

16. WALKER, N.I.; GOBÉ, G.C. Cell death and cell proliferation during atrophy of the rat parotid gland induced by duct obstruction. J Pathol, v.153, n.4, p.333-4, Dec. 1987

17.ZAIA, A.A.; ALMEIDA, O.P.; LINE, S.R.P. Immunochemical analysis of laminin in duct-ligated submandibular glands of rats. J Oral Pathol Med, v.26, n.10, p.451-3, Nov. 1997. 